\title{
Analytical Solution of Steady-State Temperature Field of Single Freezing Pipe under Action of Seepage Field
}

\author{
Bin Wang $\mathbb{D},,^{1,2}$ Chuanxin Rong $\mathbb{D},{ }^{1,2}$ Hua Cheng, ${ }^{2}$ Haibing Cai, ${ }^{2}$ and Shiqi Zhang ${ }^{2}$ \\ ${ }^{1}$ State Key Laboratory of Mining Response and Disaster Prevention and Control in Deep Coal Mine, \\ Anhui University of Science and Technology, Huainan 232001, China \\ ${ }^{2}$ School of Civil Engineering and Architecture, Anhui University of Science and Technology, Huainan 232001, China \\ Correspondence should be addressed to Chuanxin Rong; chxrong@aust.edu.cn
}

Received 31 December 2019; Revised 22 February 2020; Accepted 23 April 2020; Published 25 May 2020

Academic Editor: Yinshan Tang

Copyright (C) 2020 Bin Wang et al. This is an open access article distributed under the Creative Commons Attribution License, which permits unrestricted use, distribution, and reproduction in any medium, provided the original work is properly cited.

To accurately describe the distribution law of the temperature field formed by a single freezing pipe under the action of a seepage field, the shape of the freezing front was simplified using a segmentation-equivalent method. The analytical solution of the steadystate temperature field was derived, and the accuracy was verified using a physical model test. Combined with the results of the model test and the calculation results of the analytical solution, the distribution law of the freezing temperature field formed by a single pipe under different seepage velocities was analyzed. It was found that compared with the no flow rate, when the seepage velocity was 3, 6, and $9 \mathrm{~m} /$ day, the frozen area was reduced from $17.97 \times 10^{4} \mathrm{~mm}^{2}$ to $15.77 \times 10^{4}, 3.84 \times 10^{4}$, and $3.05 \times 10^{4} \mathrm{~mm}^{2}$, respectively. The proportion of frozen area below $-5^{\circ} \mathrm{C}$ increased from $39.43 \%$ to $40.19 \%, 49.84 \%$, and $51.52 \%$, respectively. The average freezing temperature field reduced from -5.78 to $-5.86,-7.31$, and $-7.50^{\circ} \mathrm{C}$, respectively. As the seepage velocity increased, the frozen area formed by a single pipe decreased while the proportion of the low-temperature zone increased and the average temperature of the temperature field decreased.

\section{Introduction}

The artificial formation freezing method was first proposed by Poetsch in the 19th century and was originally used in the shaft construction process in soft and water-rich soil layers. During the implementation of this method, an external refrigeration unit first reduces the low-temperature refrigerant to a negative temperature (the temperature of the brine or alcohol is generally reduced to $-40^{\circ} \mathrm{C}$, and the temperature of the liquid nitrogen can be reduced to $-190^{\circ} \mathrm{C}$ ), and a low-temperature refrigerant is subsequently pumped through each freezing pipe. The low-temperature refrigerant in the freezing pipe exchanges heat with the surrounding soil layer through the pipe wall, thereby freezing the soil layer [1-5]. This method has a little influence on the surrounding environment, and the formed frozen wall exhibits a good sealing performance and high strength as a temporary supporting structure. Therefore, this method has gradually developed into one of the main methods used in underground construction in complex strata. In recent years, in the construction of subway tunnels in coastal cities, such as Tianjin, Guangzhou, Shenzhen, and Ningbo, the freezing method has been widely used in the soil reinforcement of subway communication channels and the soil reinforcement of the import and export of shield tunnels [6-9]. Due to the influence of marine sedimentary environments, seawater impregnation, and tidal systems, the groundwater in coastal urban strata has high salinity and flow rate. When the artificial ground freezing method is adopted in these types of strata, a large difference exists in the freezing temperature field distribution law in the nonseepage flow field.

Aiming to understand the influence of the seepage field on the artificial freezing temperature field, scholars worldwide have conducted considerable related research. Many experimental studies have been conducted. Wang et al. used a model test method to experimentally study the effect of the groundwater flow rate on the freezing temperature field 
under freezing conditions created using liquid nitrogen (temperatures -57 and $-80^{\circ} \mathrm{C}$, respectively); the results showed that the groundwater with a flow rate of $10 \mathrm{~m} / \mathrm{d}$ or more had a significant effect on the freezing by use of liquid nitrogen [10]. Zhou et al. carried out an orthogonal model test of double-pipe freezing and studied the effects of the seepage velocity and pipe spacing on the closure time of the frozen wall in saturated sand layers. Furthermore, they studied the development behavior of the temperature fields upstream and downstream [11]. Pimentel et al. summarized the results of the formation behavior of the freezing temperature field under the action of groundwater. The problem of the loss of freezing capacity was fully considered, and a new test device was designed based on the predecessor devices. Large-scale model tests of artificial ground freezing under seepage conditions with flow rates of $0,1,1.5,2.0$, and $2.1 \mathrm{~m} / \mathrm{d}$ were carried out. Based on the test results, several analytical solutions of the closure time of the frozen wall were discussed [12]. Huang et al. studied the formation behavior of the single-pipe freezing temperature field under different flow rates (the maximum flow rate was $2 \mathrm{~m} / \mathrm{d}$ ) [13]. Based on the similarity theory, Li et al. established an interlaced double-row pipe freezing model test system under the action of seepage and conducted orthogonal tests on the main influencing factors for the formation of the frozen wall in the seepage stratum [14].

Several researchers have studied this problem mathematically or numerically. Victor derived a mathematical expression of the freezing temperature field of a single freezing pipe with seepage, which is the only analytical expression that accounts for the influence of the seepage velocity on the temperature field [15]. Harlan first proposed a coupled model of hydrothermal migration, and many scholars have used this result as the basis of further studies [16]. Trupak and Bakholdin proposed an analytical solution for the frozen temperature field formed by single pipe, single-row, and double-row freezing pipes $[17,18]$. Sanger and Sayles studied the distribution formula of freezing temperature field formed by a single-row pipe [19]. Tobe and Akimoto derived an analytical solution to a multipiped frozen temperature field [20]. Lai et al. obtained the governing differential equations for the problem with coupled temperature and seepage fields [21]. Yang and Pi established a mathematical model for the development of the freezing front of a single freezing pipe using the theory of heat transport in porous media and Darcy's law and analyzed the variation of the temperature field and groundwater flow field during the freezing process [22]. Xu obtained a coupled mathematical model of the temperature-seepage field including phase changes of the lowtemperature rock mass and applied the model to the analysis of engineering problems [23]. Hu et al. established a set of methods for solving the steady-state temperature field of artificial ground freezing based on the principle of superposition of potential functions. Combining this principle with mathematical methods, a series of analytical results for the steady-state temperature field were obtained [24-28]. In order to benchmark flow and energy transport models that include pore water phase change, Kurylyk et al. presented a detailed derivation of the Lunardini solution and found that the accuracy of Lunardini solution was directly proportional to the Stefan number [29]. Vitel et al. constructed a hydrothermal numerical model consistent with thermodynamics to simulate the artificial ground freezing of saturated nondeformable porous media under seepage conditions. This numerical model has been well verified by the results of three-dimensional ground freezing experiments under high seepage velocity conditions [30-32]. Marwan et al. used the "ant colony algorithm" to optimize the layout of freezing pipes under the action of low-flow-rate groundwater, thereby shortening the closure time of the frozen wall and making the strength of the frozen wall more uniform. This method led to new ideas for the optimal design of the layout of freezing pipes [33]. Scheidegger et al. proposed a combination of one-dimensional heat conduction model and two-dimensional thermal convection model including freeze-thaw action to simulate permafrost development in complex geological environments and made it possible to evaluate the influence of convective heat flow and load on the state of glaciers [34]. Based on the heat transfer and seepage theory of the finite element method in porous media, $\mathrm{Hu}$ et al. built a fully coupled numerical model to simulate changes in temperature and groundwater flow fields; the ability of the model to solve the phase transition problem was verified by the classical analysis solution of freezing temperature field, and the factors that influence the frozen wall crossing time are also analyzed [35]. Grenier et al. verified a series of the numerical codes being developed for coupled nonlinear freeze-thaw systems, and this verification effort provided a basis for addressing more general challenges related to numerical simulation of cold-region hydrogeological processes [36]. Huang et al. developed a hydrothermal coupling model to simulate the effect of water flow on the freezing process by considering the water/ice phase transition and combined the model with the Nelder-Mead simplex method based on the COMSOL Multiphysics platform to optimize the positions of the freezing pipes around a circular tunnel $[13,37,38]$. Alzoubi et al. constructed a numerical model of the hydrothermal coupling using the enthalpy-porosity method and verified the rationality of the model through experiments. Based on the model, the factors affecting the development of the freezing temperature field were studied, and the influence of the seepage field on the freezing temperature field was analyzed in depth by introducing the concept of "Heatlines" $[39,40]$.

After the artificial formation freezing enters the stable freezing stage, the temperature drop rate of the freezing temperature field becomes very slow; therefore, the transient temperature field at this time can be approximated by the steady-state temperature field [24-28]. When a seepage field exists in the stratum, after entering the stable freezing phase, the convective heat transfer between the water and the frozen soil on the freezing front and the heat transfer of the frozen pipe cancel each other out under the condition that the seepage velocity and the water temperature are constant. The temperature field at this time is close to the steady-state temperature field; therefore, it is also possible to use a steady- 
state temperature field instead of a transient temperature field for analysis.

Considerable progress has occurred in the analytical calculation of the steady-state temperature field of artificial freezing in nonseepage strata [24-28], but an analytical solution of the steady-state freezing temperature field under the action of a seepage field is lacking. The study of the freezing temperature field formed by single pipe is the basis of artificial frozen wall research and has important research value. In this paper, the analytical expression of the steadystate temperature field of single freezing pipe under the action of seepage field was derived, and the accuracy of the analytical solution was verified by physical model test. Based on the formulas provided in this paper, the temperature field formed by single freezing pipe under different seepage velocity was calculated.

\section{Analytical Solution}

2.1. Basic Assumption. Under the action of the seepage field, the water flow changes the heat distribution of the entire frozen area through the convective heat transfer, and the freezing range of the downstream area is obviously larger than the upstream area; therefore, the shape of the freezing front is no longer a circle, but a shape close to the "cardioid" $[12,15]$.

To facilitate the description of the distribution law of the freezing temperature field, a rectangular coordinate system was constructed as shown in Figure 1. The center of the freezing pipe was taken as the coordinate origin; the axis passing through the origin and parallel to the water flow direction was taken as the $x$-axis, and the axis passing through the origin and perpendicular to the water flow direction was taken as the $y$-axis.

The intersections $\mathrm{I}\left(\xi_{1}^{V}, 0\right)$ and $\operatorname{III}\left(\xi_{3}^{V}, 0\right)$ of the freezing front and the $x$-axis represent the extended range of the upstream and downstream of the freezing front under the action of the seepage field, respectively; intersection point $\mathrm{II}\left(\xi_{2}^{V}, 0\right)$ represents the extended range of the side of the freezing front. Point $\mathrm{M}\left(x_{0}, y_{0}\right)$ is any point within the freezing front of the right side of the $x$-axis $(x>0) . \mathrm{M}^{\prime}\left(x_{1}, y_{1}\right)$ is the intersection of the freezing front and straight line passing through the origin $(0,0)$ and the point $\mathrm{M}\left(x_{0}, y_{0}\right)$. $\mathrm{N}\left(x_{2}, y_{2}\right)$ is any point within the freezing front of the left side of the $x$-axis $(x<0)$ and $\mathrm{N}^{\prime}\left(x_{3}, y_{3}\right)$ is the intersection of the freezing front and straight line passing through the origin $(0$, $0)$ and the point $\mathrm{N}\left(x_{2}, y_{2}\right)$.

According to the characteristics of the steady-state freezing temperature field of a single pipe under the seepage field, before performing analytical solution derivation, the following hypotheses are proposed:

(1) The flow rate, direction, and temperature of the seepage field remain unchanged.

(2) The porous medium is uniform (particle size, porosity, and thermal conductivity are equal at all locations).

(3) The temperature of the freezing pipe wall is constant.

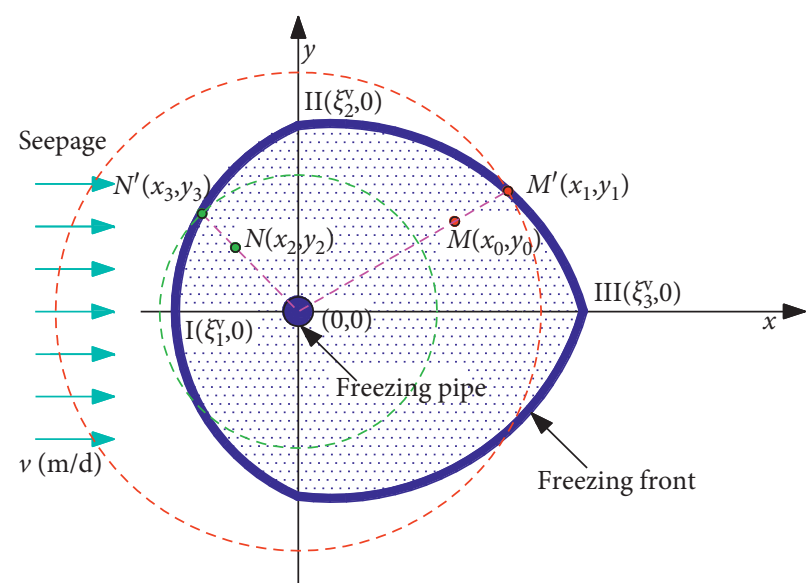

FIGURE 1: Schematic diagram of the mathematical model of steadystate temperature field of a single freezing pipe under the action of seepage field.

(4) After entering the stable freezing phase, the freezing temperature field becomes a steady-state temperature field.

(5) As shown in Figure 1, taking the $y$-axis as the dividing line, the shape of the freezing fronts on both sides of the dividing line is equivalent to half an ellipse. And the shape of the freezing front can be expressed by the following equation:

$$
\left\{\begin{array}{l}
\frac{x^{2}}{\xi_{2}^{2}}+\frac{y^{2}}{\xi_{1}^{2}}=1, \quad(x<0), \\
\frac{x^{2}}{\xi_{3}^{2}}+\frac{y^{2}}{\xi_{2}^{2}}=1, \quad(x \geq 0) .
\end{array}\right.
$$

2.2. Derivation of Analytical Solution. According to the first law of thermodynamics, the equation for two-dimensional heat conduction is expressed as [41]

$$
\frac{\partial q_{x}}{\partial x}+\frac{\partial q_{y}}{\partial y}=0
$$

where $q_{x}$ and $q_{y}$ are the heat flux densities along the $x$ and $y$ axes, respectively. [41]

According to Fourier's law, $q_{x}$ and $q_{y}$ can be expressed as

$$
\left\{\begin{array}{l}
q_{x}=-k \frac{\partial T}{\partial x}, \\
q_{y}=-k \frac{\partial T}{\partial y},
\end{array}\right.
$$

where $k$ and $T$ are the thermal conductivity and temperature of the soil, respectively.

It is assumed that the soil is isotropic in thermophysics, so $k$ was the same in all directions. And the following equation can be obtained [41]: 


$$
\frac{\partial^{2} T}{\partial x^{2}}+\frac{\partial^{2} T}{\partial y^{2}}=0
$$

The polar form of equation (5) is [41]

$$
\frac{\partial^{2} T}{\partial R^{2}}+\frac{1}{R} \frac{\partial T}{\partial R}+\frac{1}{R^{2}} \frac{\partial^{2} T}{\partial \theta^{2}}=0 .
$$

In the steady-state freezing temperature field formed by a single freezing pipe, the temperature of the freezing pipe and the freezing front are stabilized at $T_{f}$ and $T_{0}$, respectively. Therefore, the boundary conditions are as follows:

$$
T= \begin{cases}T_{f}, & r=r_{0} \\ T_{0}, & r=\xi(x, y, v)\end{cases}
$$

where $T_{0}$ is the freezing temperature of the soil, $T_{f}$ is the temperature of the freezing pipe, $r_{0}$ is the radius of the freezing pipe, and $\xi$ is the distance from the freezing front to the center of the freezing pipe. Under the action of flowing water, the shape of the freezing front is no longer a circle, and $\xi$ changes with position $(x, y)$ and seepage velocity $v$.

The freezing front is considered to consist of countless points. For any point where the distance from the freezing front to the freezing pipe is $\xi$, the point can also be regarded as a point on the circle with the freezing pipe as the center and the radius of $\xi$, as shown in Figure 1. According to the calculation principle of steady-state freezing temperature field of a single pipe $[17,26,28]$ and combining equations (6) and (7), the following equation is obtained:

$$
T=T_{0}+\frac{\ln (r / \xi)}{\ln \left(r_{0} / \xi\right)}\left(T_{f}-T_{0}\right)
$$

When $x \geq 0$, the straight line passing through the point $\mathrm{M}\left(x_{0}, y_{0}\right)$ and the origin $(0,0)$ can be expressed as

$$
y=\frac{y_{0}}{x_{0}} x
$$

The expressions of the intersection $\mathrm{M}^{\prime}\left(x_{1}, y_{1}\right)$ of the straight line and the freezing front can be obtained by combining equations (2) and (9):

$$
\left\{\begin{array}{l}
x_{1}=\frac{x_{0} \xi_{2} \xi_{3}}{\sqrt{\xi_{2}^{2} x_{0}^{2}+\xi_{3}^{2} y_{0}^{2}}}, \\
y_{1}=\frac{y_{0} \xi_{2} \xi_{3}}{\sqrt{\xi_{2}^{2} x_{0}^{2}+\xi_{3}^{2} y_{0}^{2}}} .
\end{array}\right.
$$

$0)$ is

The distance from $\mathrm{M}^{\prime}\left(x_{1}, y_{1}\right)$ to the coordinate origin ( 0 ,

$$
\xi=\sqrt{x_{1}^{2}+y_{1}^{2}}=\frac{\xi_{2} \xi_{3} \sqrt{x_{0}^{2}+y_{0}^{2}}}{\sqrt{\xi_{2}^{2} x_{0}^{2}+\xi_{3}^{2} y_{0}^{2}}}
$$

Substitution of equation (11) into equation (8) yields

$$
T=T_{0}+\frac{\ln \left(\sqrt{x_{0}^{2}+y_{0}^{2}} /\left(\xi_{2} \xi_{3} \sqrt{x_{0}^{2}+y_{0}^{2}} / \sqrt{\xi_{2}^{2} x_{0}^{2}+\xi_{3}^{2} y_{0}^{2}}\right)\right)}{\ln \left(r_{0} /\left(\xi_{2} \xi_{3} \sqrt{x_{0}^{2}+y_{0}^{2}} / \sqrt{\xi_{2}^{2} x_{0}^{2}+\xi_{3}^{2} y_{0}^{2}}\right)\right)}\left(T_{f}-T_{0}\right)(x \geq 0) .
$$

The temperature expression at any point in the frozen region $(x \geq 0)$ is obtained by simplifying the following equation:

$$
T=T_{0}+\frac{\ln \left(\sqrt{\xi_{2}^{2} x^{2}+\xi_{3}^{2} y^{2}} / \xi_{2} \xi_{3}\right)}{\ln \left(r_{0} \sqrt{\xi_{2}^{2} x^{2}+\xi_{3}^{2} y^{2}} /\left(\xi_{2} \xi_{3} \sqrt{x^{2}+y^{2}}\right)\right)}\left(T_{f}-T_{0}\right)(x \geq 0) .
$$

When $x<0$, the straight line passing through the point $\mathrm{N}\left(x_{2}, y_{2}\right)$ and the origin $(0,0)$ can be expressed as

$$
y=\frac{y_{2}}{x_{2}} x
$$

The expressions of the intersection $\mathrm{N}^{\prime}\left(x_{3}, y_{3}\right)$ of the straight line and the freezing front can be obtained by combining equations (2) and (14):

$$
\left\{\begin{array}{l}
x_{3}=\frac{x_{2} \xi_{1} \xi_{2}}{\sqrt{\xi_{1}^{2} x_{2}^{2}+\xi_{2}^{2} y_{2}^{2}}} \\
y_{3}=\frac{y_{2} \xi_{1} \xi_{2}}{\sqrt{\xi_{1}^{2} x_{2}^{2}+\xi_{2}^{2} y_{2}^{2}}} .
\end{array}\right.
$$
$0)$ is

The distance from $\mathrm{N}^{\prime}\left(x_{3}, y_{3}\right)$ to the coordinate origin $(0$,

$$
\xi_{\prime}=\sqrt{x_{3}^{2}+y_{3}^{2}}=\frac{\xi_{1} \xi_{2} \sqrt{x_{2}^{2}+y_{2}^{2}}}{\sqrt{\xi_{1}^{2} x_{2}^{2}+\xi_{2}^{2} y_{2}^{2}}}
$$

Substituting equation (16) into equation (8) and considering the arbitrariness of $\mathrm{N}\left(x_{2}, y_{2}\right)$, the temperature expression at any point in the frozen area $(x<0)$ is

$$
T=T_{0}+\frac{\ln \left(\sqrt{\xi_{1}^{2} x^{2}+\xi_{2}^{2} y^{2}} / \xi_{1} \xi_{2}\right)}{\ln \left(r_{0} \sqrt{\xi_{1}^{2} x^{2}+\xi_{2}^{2} y^{2}} /\left(\xi_{1} \xi_{2} \sqrt{x^{2}+y^{2}}\right)\right)}\left(T_{f}-T_{0}\right)(x<0) .
$$


When the seepage velocity is $0 \mathrm{~m} /$ day, $\xi_{1}=\xi_{2}=\xi_{3}=\xi$. At this time, equations (13) and (17) are simplified to

$$
T=T_{0}+\frac{\ln (r / \xi)}{\ln \left(r_{0} / \xi\right)}\left(T_{f}-T_{0}\right)
$$

where $r=\sqrt{x^{2}+y^{2}}$.

Equation (18) is the same as the Trupak formula [17] of the temperature field formed by single freezing pipe without seepage.

Based on equations (13) and (17), the formula for the isotherm of any temperature $\mathrm{T}$ can be derived as

$$
\begin{cases}\frac{\left(\xi_{2}^{2} x^{2}+\xi_{3}^{2} y^{2}\right)^{m-1}}{\left(x^{2}+y^{2}\right)^{m}}=A, \quad(x \geq 0), \\ \frac{\left(\xi_{2}^{2} x^{2}+\xi_{1}^{2} y^{2}\right)^{m-1}}{\left(x^{2}+y^{2}\right)^{m}}=B, \quad(x<0),\end{cases}
$$

where

$$
\begin{aligned}
& A=\frac{\left(\xi_{2} \xi_{3}\right)^{2(m-1)}}{r_{0}^{2 m}}, \\
& B=\frac{\left(\xi_{1} \xi_{2}\right)^{2(m-1)}}{r_{0}^{2 m}}, \\
& m=\frac{T-T_{0}}{T_{f}-T_{0}} .
\end{aligned}
$$

At the wall of the freezing pipe, $T=T_{f}$, equation (20) is simplified as

$$
\begin{cases}\frac{1}{\left(x^{2}+y^{2}\right)}=\frac{1}{r_{0}^{2}}, & (x>0), \\ \frac{1}{\left(x^{2}+y^{2}\right)}=\frac{1}{r_{0}^{2}}, & (x<0) .\end{cases}
$$

At the freezing front $T=T_{0}$, equation (20) is simplified as

$$
\begin{cases}\frac{1}{\left(\xi_{2}^{2} x^{2}+\xi_{3}^{2} y^{2}\right)}=\frac{1}{\xi_{2}^{2} \xi_{3}^{2}}, & (x \geq 0), \\ \frac{1}{\left(\xi_{2}^{2} x^{2}+\xi_{1}^{2} y^{2}\right)}=\frac{1}{\xi_{1}^{2} \xi_{2}^{2}}, & (x<0) .\end{cases}
$$

The expression for the extension radius $\xi_{i}$ of the isotherm of any temperature $(T)$ in equation (20) is

$$
\left\{\begin{array}{l}
\xi_{1-T}=\frac{r_{0}^{m}}{\xi_{1}^{m-1}}, \\
\xi_{2-T}=\frac{r_{0}^{m}}{\xi_{2}^{m-1}}, \\
\xi_{3-T}=\frac{r_{0}^{m}}{\xi_{3}^{m-1}} .
\end{array}\right.
$$

The frozen area surrounded by any isotherm can be expressed as

$$
S_{T}=\frac{\pi}{2} \frac{r_{0}^{m}}{\xi_{2}^{m-1}}\left(\frac{r_{0}^{m}}{\xi_{1}^{m-1}}+\frac{r_{0}^{m}}{\xi_{3}^{m-1}}\right)-\pi r_{0}^{2} .
$$

The frozen area in any temperature range $(T, T-\Delta)$ is

$$
S_{(T, T-\Delta)}=\frac{\pi}{2}\left[\frac{r_{0}^{m_{T}}}{\xi_{2}^{m_{T}-1}}\left(\frac{r_{0}^{m_{T}}}{\xi_{1}^{m_{T}-1}}+\frac{r_{0}^{m_{T}}}{\xi_{3}^{m_{T}-1}}\right)-\frac{r_{0}^{m_{T-\Delta}}}{\xi_{2}^{m_{T-\Delta}-1}}\left(\frac{r_{0}^{m_{T-\Delta}}}{\xi_{1}^{m_{T-\Delta}-1}}+\frac{r_{0}^{m}}{\xi_{3}^{m_{T-\Delta}-1}}\right)\right] .
$$

\section{Hydrothermal Model Test}

3.1. Model Test Design. To verify the rationality of the analytical solution, a large-scale physical model test system was designed. The whole test system consists of a porous medium test zone, a freezing system, a seepage field simulation system, and a data acquisition system, as shown in Figure 2.

The test plane was set at $500 \mathrm{~mm}$ intervals in the box, the test plane consisted of 7 axes labeled A-G, and 13 measurement points were arranged on each axis. The spacing between the measurement points was $50 \mathrm{~mm}$ and that between adjacent axes was $200 \mathrm{~mm}$. The arrangement of measurement points is shown in Figure 3. In the test, only the freezing pipe in the middle position is in the working state.

In this study, a total of 4 sets of tests were conducted, the control parameters of the seepage field in the test are shown in Table 1.

The wall temperature of the inlet pipe was taken as the main reference, and its temperature was controlled at $-30^{\circ} \mathrm{C}$. To reach this temperature and account for the cooling loss in the pipeline, the alcohol temperature and flow rate of the refrigeration unit were set to $-32^{\circ} \mathrm{C}$ and $2.5 \mathrm{~m}^{3} / \mathrm{h}$, respectively.

3.2. Analysis of Steady-State Temperature Field of Model Test. The spatial distribution laws of the temperature of each measuring point $(\mathrm{D} 1-13)$ on the $\mathrm{D}$ axis were plotted as graphs, as shown in Figure 4.

Figure 4 shows that when no seepage occurred in the saturated porous medium, the temperatures at the measurement points located at the symmetric positions on the $\mathrm{D}$ axis were basically the same at the same time, indicating that the positions of the measurement points were relatively accurate and the sand layer was relatively uniform. The spacing between adjacent two curves in the late stage of freezing gradually decreased, indicating that the temperature drop of the freezing temperature field became slower after entering the relatively stable stage in the late stage of freezing. The curve with the freezing time of $24 \mathrm{~h}$ and the curve of $28 \mathrm{~h}$ basically coincided, so it can be considered that the freezing temperature field entered the stable freezing stage when the freezing time was $28 \mathrm{~h}$.

When $v=3 \mathrm{~m} /$ day, the temperatures at the measurement points located in the downstream area were lower than those at the measurement points in the upstream area, indicating that the convective heat transfer of the water flow changed 


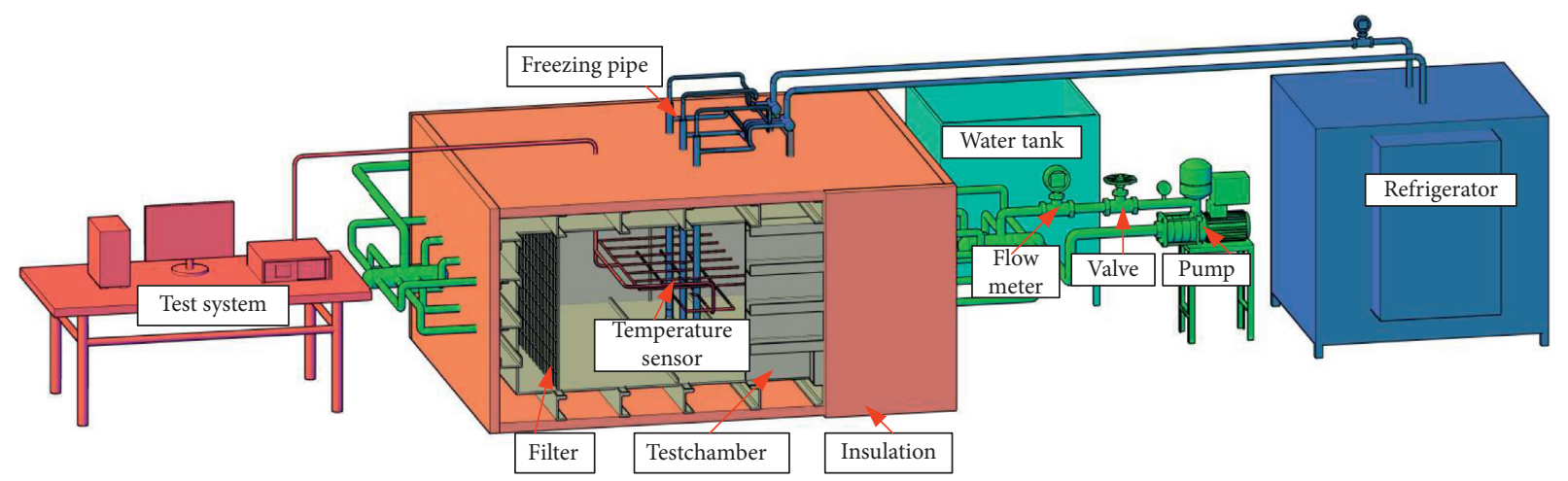

FIgURE 2: Three-dimensional (3D) schematic of the large-scale physical model test system.

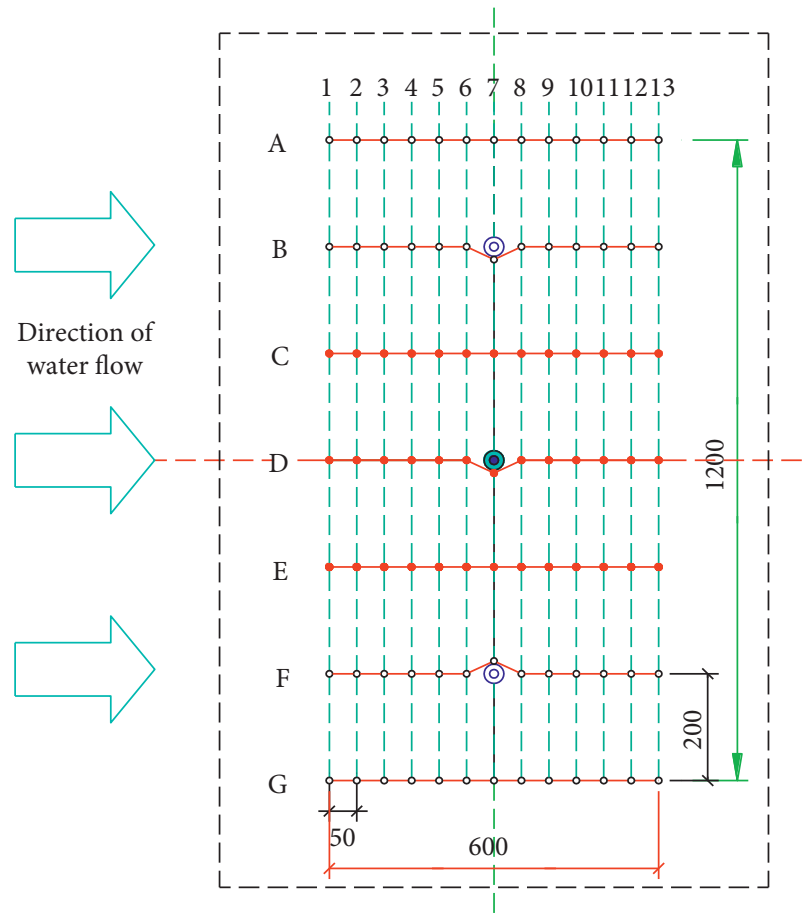

Figure 3: Schematic diagram of temperature measurement point layout (note: the color-filled freezing pipe is in the working state, and the other two freezing pipes are closed).

TABLE 1: Relationship between seepage velocity and water flow in the test.

\begin{tabular}{lcc}
\hline Seepage velocity & Water flow & Water temperature \\
\hline 0 & 0 & - \\
$3 \mathrm{~m} /$ day & $0.25 \mathrm{~m}^{3} / \mathrm{h}$ & $15^{\circ} \mathrm{C}$ \\
$6 \mathrm{~m} /$ day & $0.50 \mathrm{~m}^{3} / \mathrm{h}$ & $15^{\circ} \mathrm{C}$ \\
$9 \mathrm{~m} /$ day & $0.75 \mathrm{~m}^{3} / \mathrm{h}$ & $15^{\circ} \mathrm{C}$ \\
\hline
\end{tabular}

the spatial distribution of the heat of the frozen area. The water was cooled as it flowed through the upstream region, the temperature difference between the water flow and the porous medium decreased, and the convective heat transfer weakened when flowing in the downstream region. Thus, the temperature drop rate at the measurement point in the downstream region was higher in the early stage of freezing.
As the freezing time increased, the downstream area gradually entered the stable freezing stage and the frozen range no longer changed, whereas the temperatures at the measurement points in the upstream area continued to decrease. Therefore, the temperature difference between the upstream and downstream regions decreased during the late stage of freezing. The parts of the curves below $0^{\circ} \mathrm{C}$ with freezing times of $36 \mathrm{~h}$ and $40 \mathrm{~h}$ basically coincided, so it can be considered that the freezing temperature field entered the stable freezing stage when the freezing time was $40 \mathrm{~h}$ with the seepage velocity being $3 \mathrm{~m} / \mathrm{d}$.

When $v=6 \mathrm{~m} /$ day, the temperature of D1-D4 measurement points in the upstream area was maintained at about $15^{\circ} \mathrm{C}$, indicating that under this flow rate condition, the freezing pipe could not affect the area beyond $150 \mathrm{~mm}$ upstream. The temperatures at the measurement points in the downstream region gradually decreased as the distance from the freezing pipe decreased; the shorter the distance from the freezing pipe, the larger the temperature gradient of the adjacent measurement points. The upstream part of the temperature distribution curves at different times was almost coincident, whereas the curves of the downstream part gradually decreased. The two curves with freezing times of $20 \mathrm{~h}$ and $24 \mathrm{~h}$ were coincident, indicating that the freezing temperature field entered a stable freezing stage when the freezing time was $24 \mathrm{~h}$ with a seepage velocity of $6 \mathrm{~m} /$ day.

When $v=9 \mathrm{~m} /$ day, the temperature at D1-D5 measurement points in the upstream area was about the same during the initial stage of freezing, and only the temperature at D5 slightly decreased during the late freezing stage. This showed that under this flow rate condition, the influence of the freezing pipe on the area outside the $100 \mathrm{~mm}$ range was weak. The temperatures at the measurement points in the downstream area gradually decreased as the distance from the freezing pipe decreased; the shorter the distance from the freezing pipe, the larger the temperature gradient of the adjacent measurement points. The three temperature curves for 16,20 , and $24 \mathrm{~h}$ coincided, indicating that the freezing temperature field entered a stable freezing stage when the freezing time was $20 \mathrm{~h}$ with a seepage velocity of $9 \mathrm{~m} /$ day.

By comparing the temperature curves under several flow conditions, it can be found that in the initial freezing period, the larger the seepage velocity, the lower the temperature in the downstream region, and in the late freezing period, the 


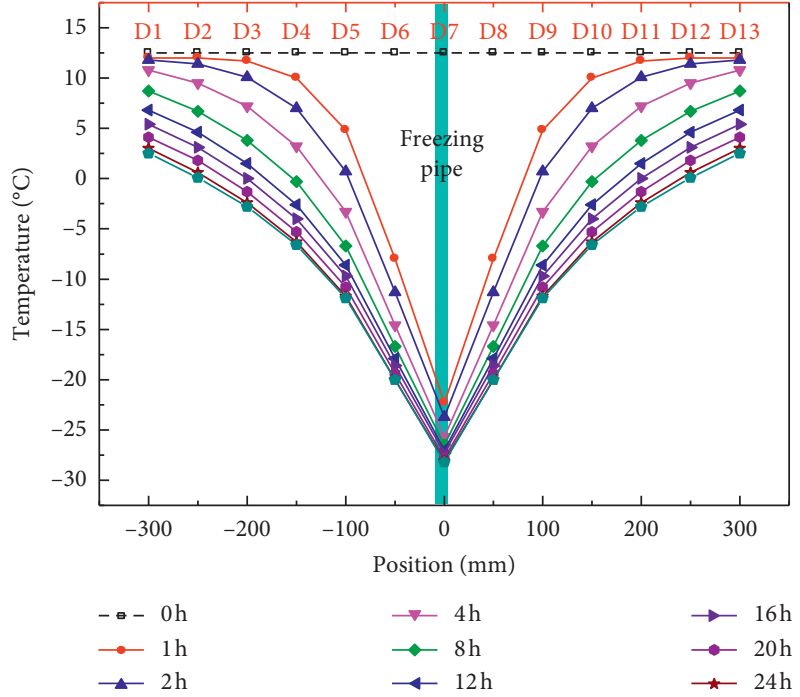

(a)

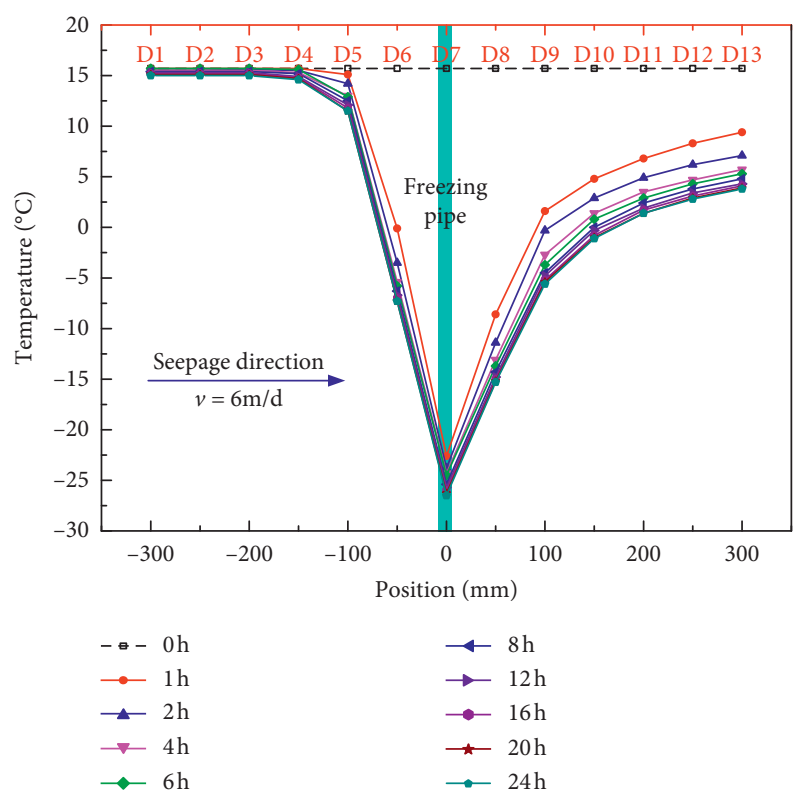

(c)

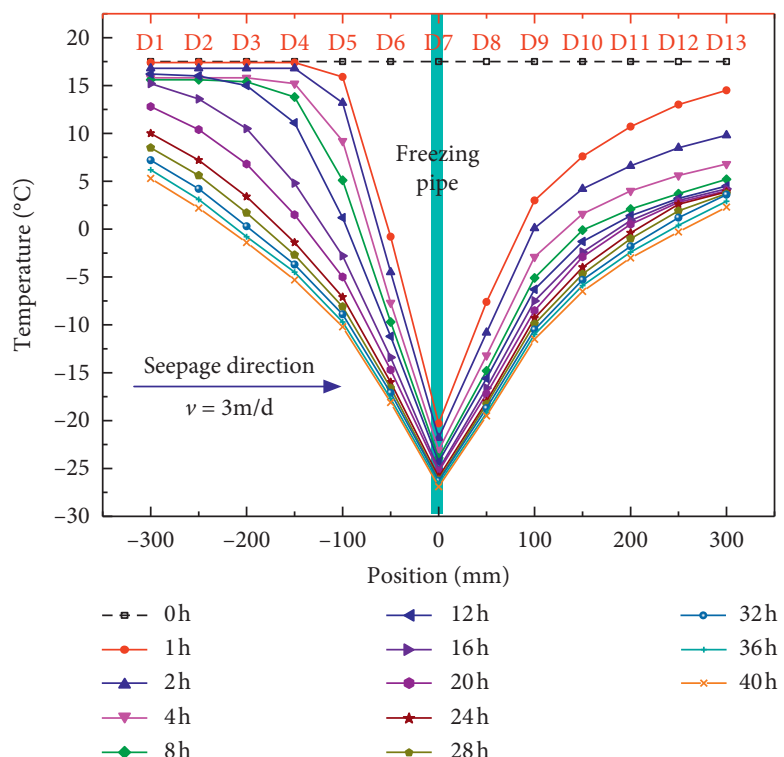

(b)
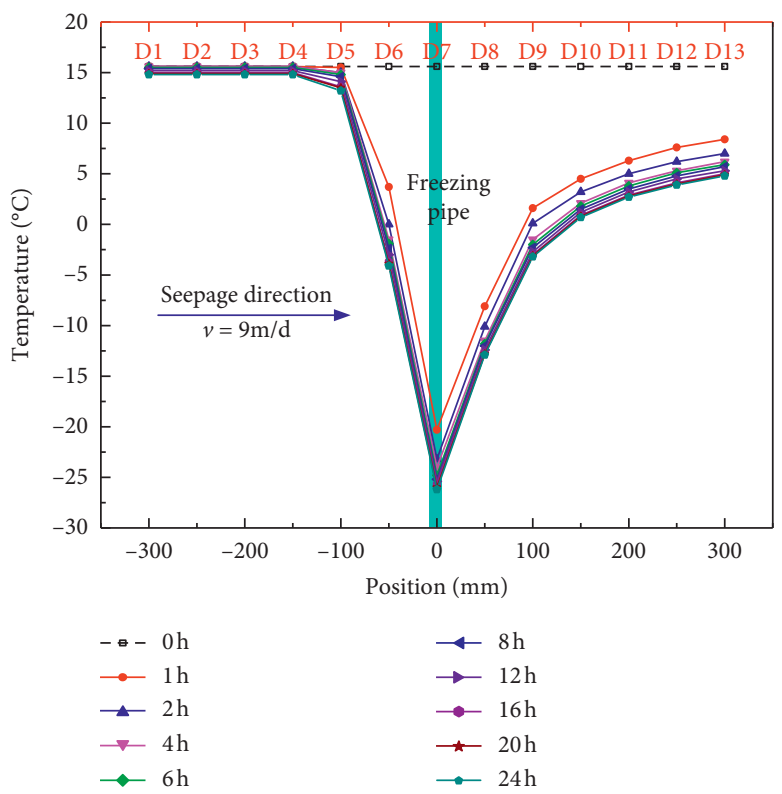

(d)

FIGURE 4: Spatial distribution of temperature on the D axis under the action of seepage field with a flow rate of (a) 0 , (b) 3, (c) 6, and (d) $9 \mathrm{~m} /$ day.

smaller the seepage velocity, the lower the temperature in the downstream region. The reasons for this phenomenon are as follows: during the construction of the artificial ground freezing method, when there is a seepage field in the local layer, due to the convective heat transfer effect, the water flow will release heat when it passes through the freezing front, and the temperature of the water flow will decrease; when low-temperature water flows to downstream area where the temperature is higher, it absorbs heat and the temperature of the downstream formation decreases. In the initial stage of freezing, the difference in freezing area is small. The greater the seepage velocity, the more intense the convective heat transfer effect and the lower the temperature in the downstream area. As the freezing time increases, the difference between the frozen area at high seepage velocity and the frozen area at low seepage velocity increases. When the seepage velocity in the ground layer is small, the contact surface between the water flow and the freezing front is larger, which results in lower temperature of the water flowing to the downstream area than that with high seepage velocity. Therefore, the lower the seepage velocity in the formation, the lower the temperature in the downstream area in the late stage of freezing.

According to the temperature test results, the extended radius $\xi_{i}$ of the freezing front of the steady-state temperature field in the three directions is shown in Table 2. The variation 
TABLE 2: Comparison of extended range of steady-state temperature field under different seepage velocities $(v)$.

\begin{tabular}{lcccccc}
\hline$v(\mathrm{~m} /$ day $)$ & $t(\mathrm{~h})$ & $\xi_{1}$ & $\xi_{2}$ & $\xi_{3}$ & $T_{f}\left({ }^{\circ} \mathrm{C}\right)$ & $T_{0}\left({ }^{\circ} \mathrm{C}\right)$ \\
\hline 0 & 28 & 240 & 234 & 240 & -27.0 & 0 \\
3 & 40 & 220 & 220 & 240 & -26.9 & \\
6 & 24 & 65 & 108 & 169 & -26.6 & \\
9 & 20 & 55 & 101 & 145 & -26.5 & \\
\hline
\end{tabular}

law of the extended radius $\xi_{i}$ with the flow rate is shown in Figure 5 , where $t$ is the time required for the freezing temperature field to enter the stable freezing section. $\xi_{1}, \xi_{2}$, and $\xi_{3}$ are the extended radii of the freezing front facing the upstream, both sides, and the downstream direction of the freezing pipe, respectively.

Table 2 and Figure 5 show that the extended radius $\xi_{i}$ of the freezing front of the steady-state freezing temperature field had three significant phases with the change in the seepage velocity $v$. When the seepage velocity $v$ was lower than $3 \mathrm{~m} /$ day, $\xi_{i}$ changed little with the seepage velocity, and the differences between the extended radii $\xi_{1}, \xi_{2}$, and $\xi_{3}$ in each direction were small. When $v$ increased from 3 to $6 \mathrm{~m} /$ day, $\xi_{1}, \xi_{2}$, and $\xi_{3}$ sharply reduced from 220,220 , and $240 \mathrm{~mm}$ to 65,108 , and $169 \mathrm{~mm}$, and the reduction ratio was $70.45 \%, 50.90 \%$, and $29.58 \%$, respectively. The gap between $\xi_{1}, \xi_{2}$, and $\xi_{3}$ at this stage gradually increased as the flow rate increased. When the seepage velocity $v$ was greater than $6 \mathrm{~m} /$ day, the expansion radius $\xi_{i}$ of the frozen area in three directions was further reduced, but the overall variation was small.

The main reasons for the above phenomena are as follows: the development law of the freezing temperature field under the action of a seepage field was the result of the interaction of heat conduction and convection heat transfer, whereas the steady-state freezing temperature field was a state in which the two effects reached equilibrium. When the seepage velocity was low, the convective heat transfer effect was weak; therefore, when $v$ increased from 0 to $3 \mathrm{~m} /$ day, the change in the extended radius $\xi_{i}$ of the freezing front of the steady-state freezing temperature field was small. The convective heat transfer was enhanced with the increase in the seepage velocity, and the heat transfer between the soil layer and the freezing pipe far from the freezing pipe was offset by convective heat transfer. Therefore, when $v$ increased from 3 to $6 \mathrm{~m} /$ day, the frozen area drastically reduced. When the frozen area reduced to a position close to the freezing pipe, the heat conduction in the frozen area became very strong. At this time, the increase in the seepage velocity had less influence on the frozen area. Therefore, when the seepage velocity was larger than $6 \mathrm{~m} /$ day, the change in $\xi_{i}$ with seepage velocity was small.

3.3. Rationality Verification of Analytical Solution. The calculation results and the test results of the temperature on the axis parallel to the direction of water flow and perpendicular to the direction of water flow under different seepage speed conditions were compared, as shown in Figures 6(a) and 6(b), respectively.

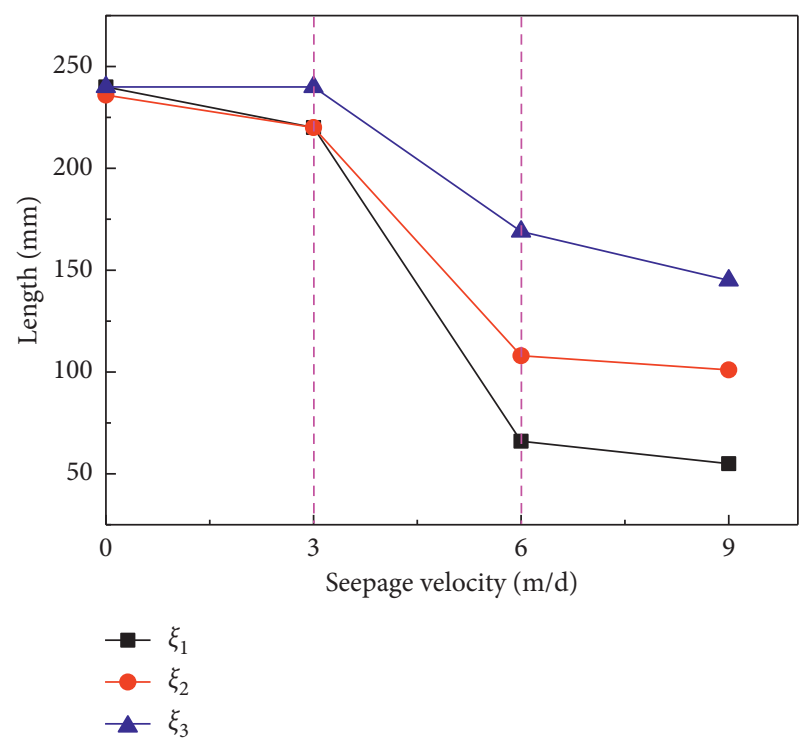

FIgURE 5: The variation law of the extended radius $\xi_{i}$ with the seepage velocity.

By comparison, we found that the formula calculation results had a high degree of agreement with the test results. Therefore, a mathematical description of the steady-state temperature field under the action of seepage field can be realized based on this formula.

\section{Calculation and Analysis of Steady-State Temperature Field of Single Freezing Pipe under Action of Seepage Field}

The test results only partially reflect the distribution law of the freezing temperature field due to the limited number of measuring points in the test. However, based on the analytical solution of the steady-state freezing temperature field under the seepage field that was derived from this study, the distribution law of the freezing temperature field was comprehensively described. Based on the formula derived from this study, the overall distribution law of the freezing temperature field under different seepage velocities was obtained, as shown in Figure 7.

Figure 7 shows that the expansion of the radius of the frozen area in all directions was equal without a seepage field, and the temperature of the frozen area dropped sharply as the distance from the freezing pipe decreased. When the seepage velocity was $3 \mathrm{~m} /$ day, after entering the stable freezing phase, the frozen zone upstream of the freezing pipe and on both sides of the freezing pipe was slightly reduced compared to that without seepage. It showed that the seepage field with velocity of $3 \mathrm{~m} / \mathrm{d}$ would reduce the temperature drop rate of the freezing temperature field formed by single pipe, but it did not have a significant effect on the temperature distribution of the steady-state temperature field compared to that without seepage. When the seepage velocity was $6 \mathrm{~m} /$ day, the convective heat transfer between the water flow and the frozen zone intensified, so the frozen zone area drastically reduced. Since the upstream 

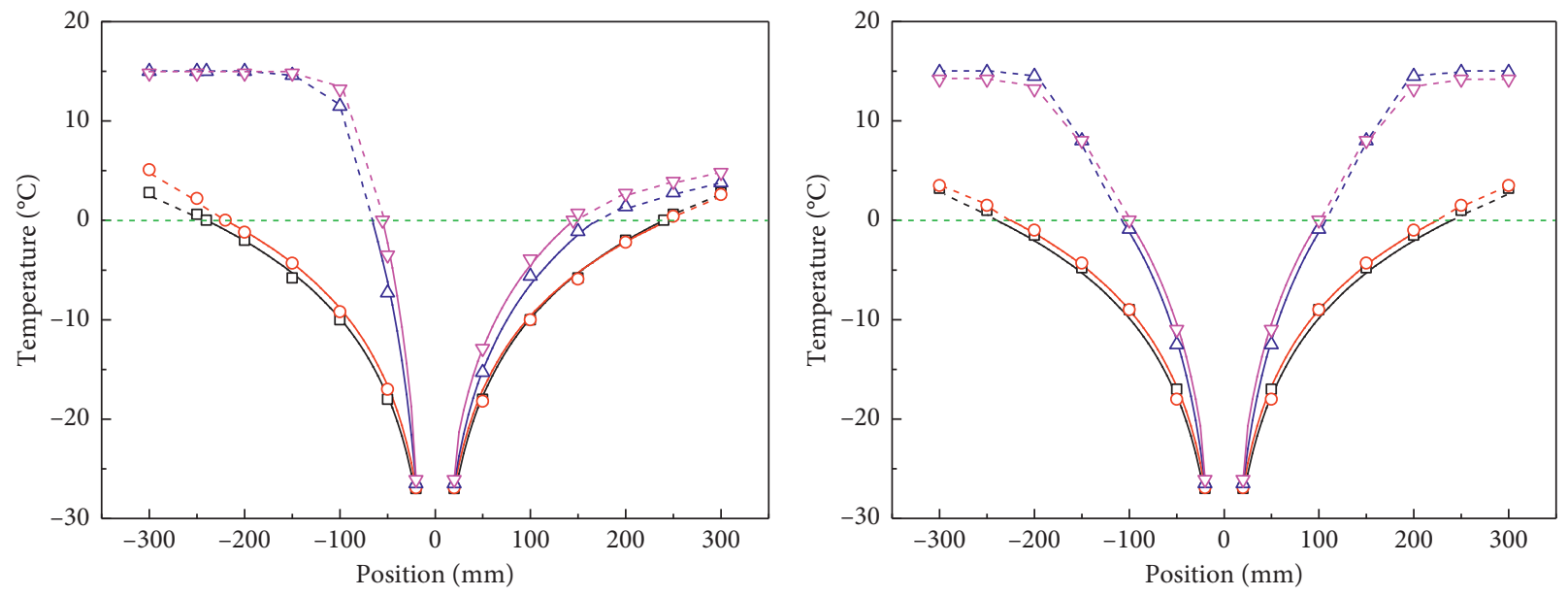

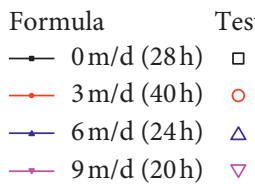

$$
\begin{aligned}
& \text { Formula Test } \\
& \text { - } 0 \mathrm{~m} / \mathrm{d}(28 \mathrm{~h}) \quad \text { 口 } \\
& \rightarrow 3 \mathrm{~m} / \mathrm{d}(40 \mathrm{~h}) \text { 。 } \\
& \rightarrow 6 \mathrm{~m} / \mathrm{d}(24 \mathrm{~h}) \Delta \\
& \rightarrow 9 \mathrm{~m} / \mathrm{d}(20 \mathrm{~h}) \quad \nabla
\end{aligned}
$$

(a)

(b)

Figure 6: Comparison between formula calculation results and test results (a) parallel and (b) perpendicular to the direction of water flow.

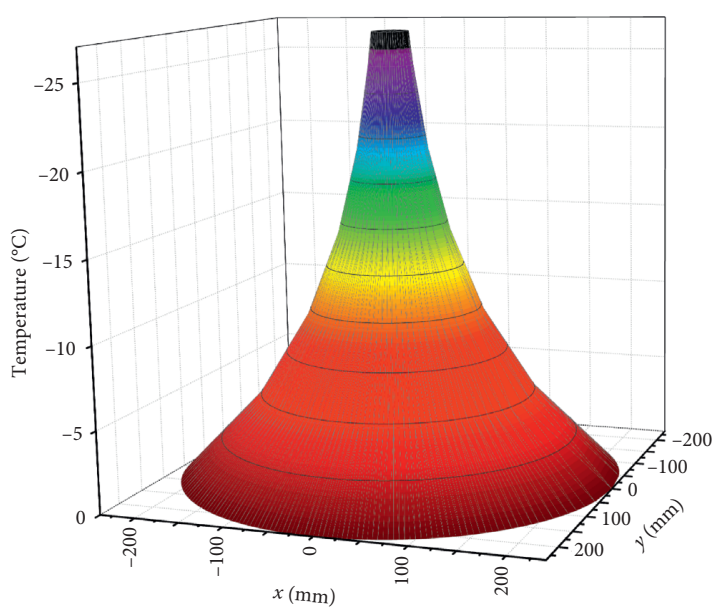

(a)

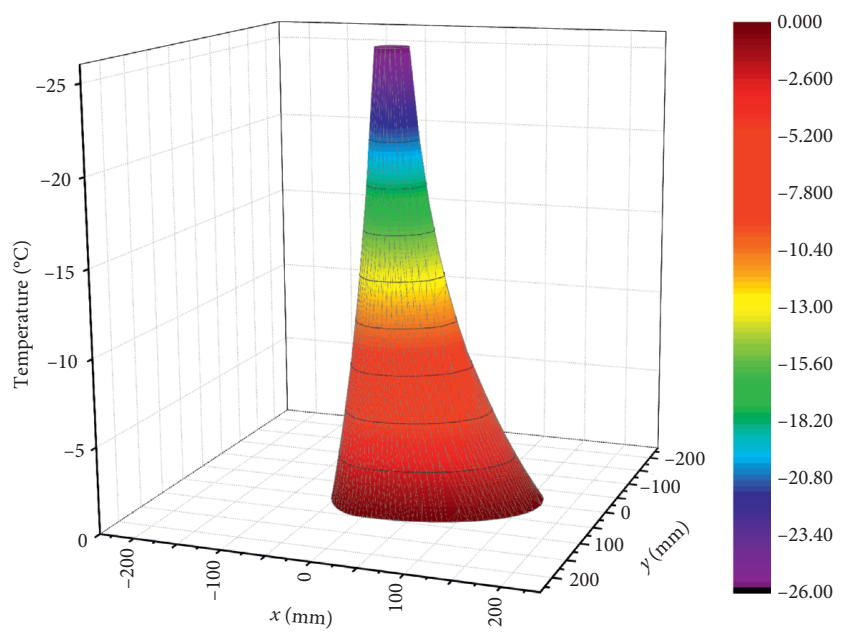

(c)

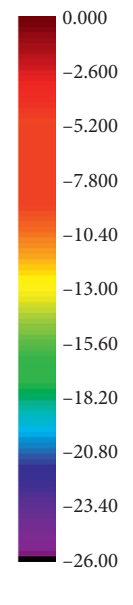

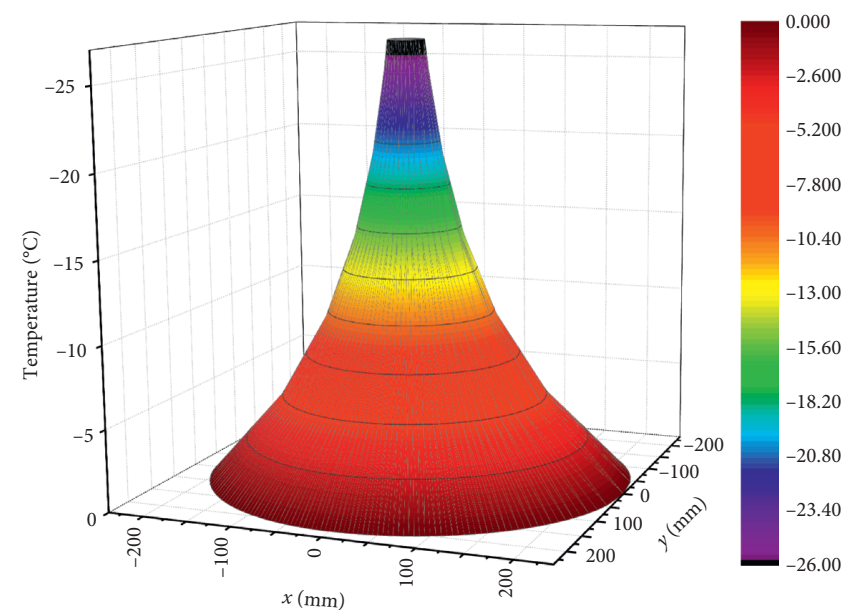

(b)

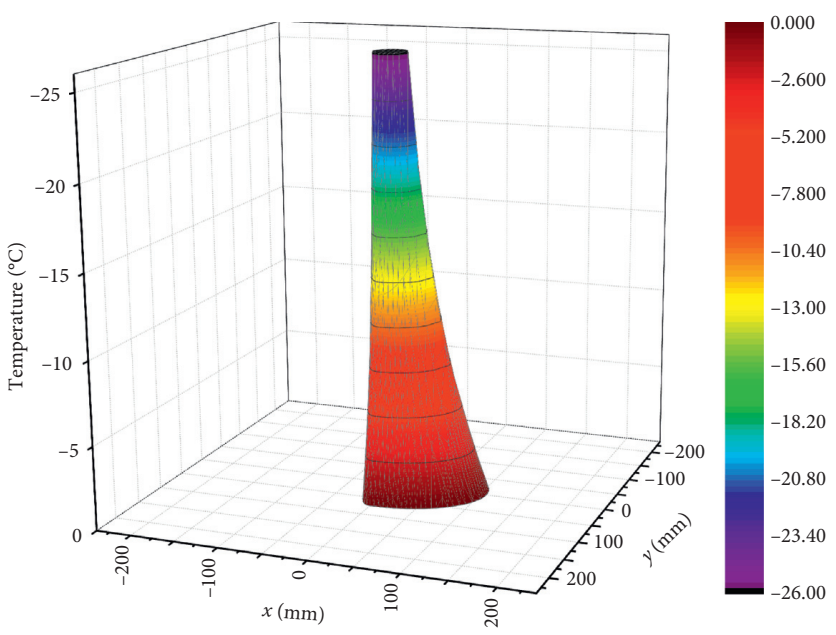

(d)

FiguRE 7: Overall distribution of steady-state freezing temperature field under the action of seepage field with a flow rate of (a) 0, (b) 3, (c) 6, and (d) $9 \mathrm{~m} /$ day. 


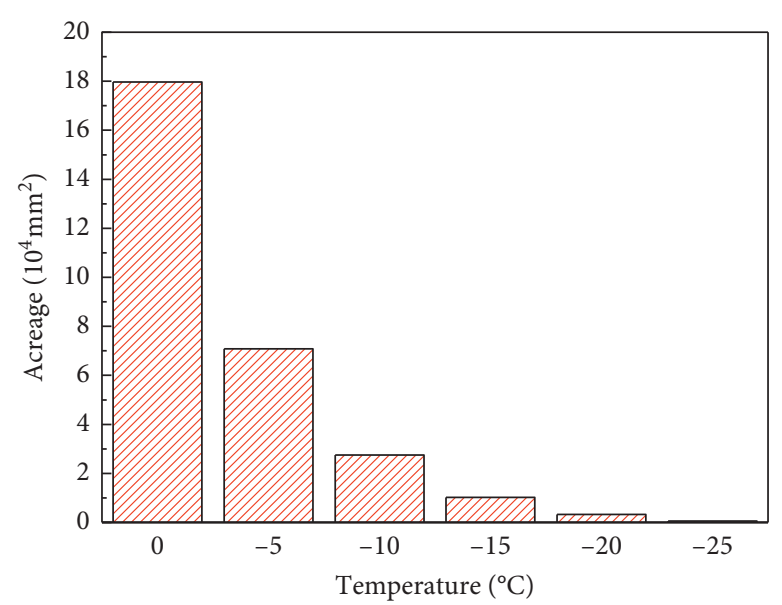

WII Acreage of frozen area

(a)

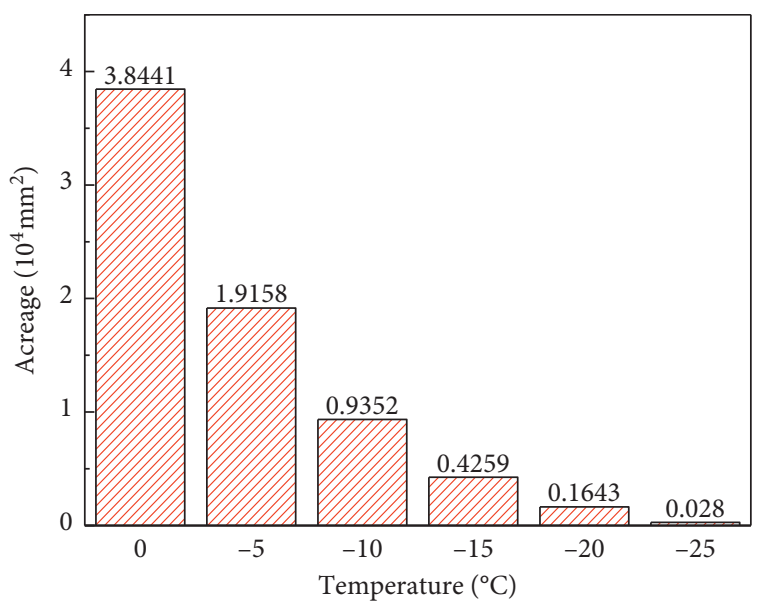

Acreage of frozen area

(c)

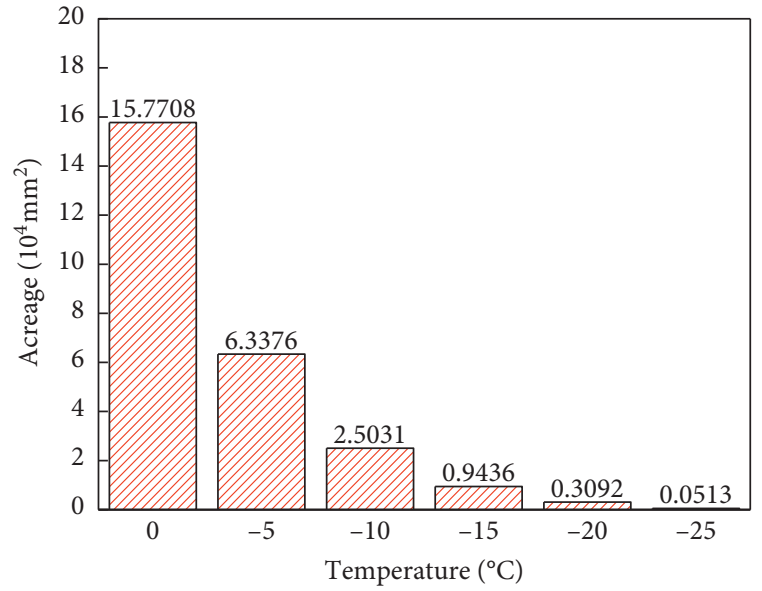

VID Acreage of frozen area

(b)

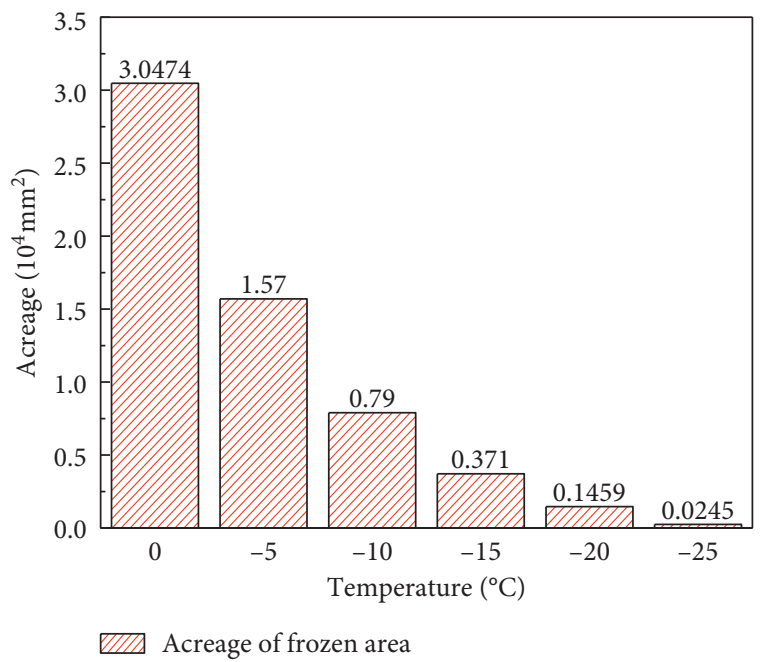

(d)

Figure 8: Frozen area surrounded by isotherms at different temperatures under the action of seepage field with a flow rate of (a) 0 , (b) 3, (c) 6 , and (d) $9 \mathrm{~m} /$ day.

position was affected by the frontal impact of the water flow, the frozen area of upstream position was significantly smaller than that of the frozen areas downstream and on both sides of freezing pipe. When the seepage velocity was $9 \mathrm{~m} /$ day, the range of the frozen area further decreased, but the overall distribution law of the temperature field was close to that with a seepage velocity of $6 \mathrm{~m} /$ day.

Using equations (23) and (24), the expansion of any one isotherm in the frozen temperature field and the area enclosed by any isotherm can be calculated, respectively. The calculation results are shown in Figure 8.

Figure 8 (a) shows that without a seepage field, the area surrounded by the $0^{\circ} \mathrm{C}$ isotherm was $17.97 \times 10^{4} \mathrm{~mm}^{2}$. As the temperature decreased, the area enclosed by the isotherm decreased sharply, and the area enclosed by the $-5^{\circ} \mathrm{C}$ isotherm was $7.09 \times 10^{4} \mathrm{~mm}^{2}$, accounting for $39.45 \%$ of the total frozen area, whereas the area enclosed by the $-25^{\circ} \mathrm{C}$ isotherm had an area of $0.06 \times 10^{4} \mathrm{~mm}^{2}$, which was only $0.31 \%$ of the total frozen area. When a seepage field existed in the sand layer, the change law of the area enclosed by the isotherm at different temperatures was the same as that with no seepage field; the area enclosed by the isotherm decreased sharply as the temperature decreased. However, due to the convective heat transfer between the seepage field and the temperature field, the frozen area formed by a single freezing pipe was smaller than that without a flow rate. When $v$ was $3 \mathrm{~m} /$ day, the area enclosed by the $0^{\circ} \mathrm{C}$ isotherm was $15.77 \times 10^{4} \mathrm{~mm}^{2}$, which was $12.24 \%$ lower than that without a flow rate. However, when $v$ was 6 and $9 \mathrm{~m} /$ day, the area enclosed by the $0^{\circ} \mathrm{C}$ isotherm was only $3.84 \times 10^{4}$ and $3.05 \times 10^{4} \mathrm{~mm}^{2}$, respectively, which are $78.63 \%$ and $83.03 \%$ lower than that without flow rate, respectively. This indicated that the seepage with a velocity greater than $6 \mathrm{~m}$ /day had a significant effect on the extended range of the steady-state temperature field of the single freezing pipe.

The frozen area between any temperature range was calculated using equation (23). The proportional relationship between the frozen area $S_{(T, T-\Delta)}$ of the temperature 


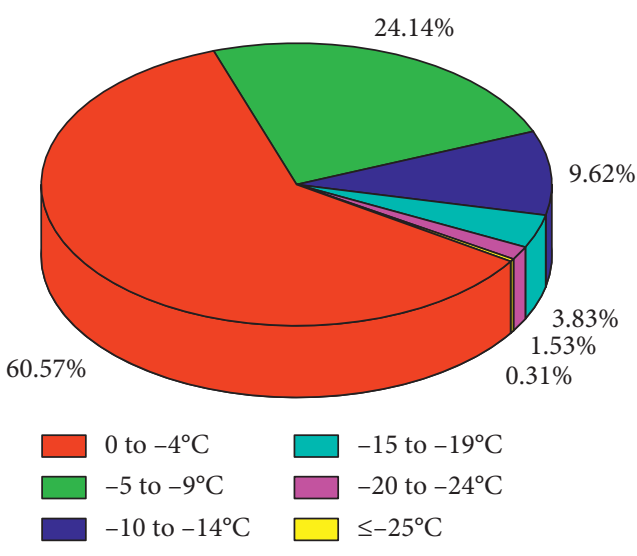

(a)

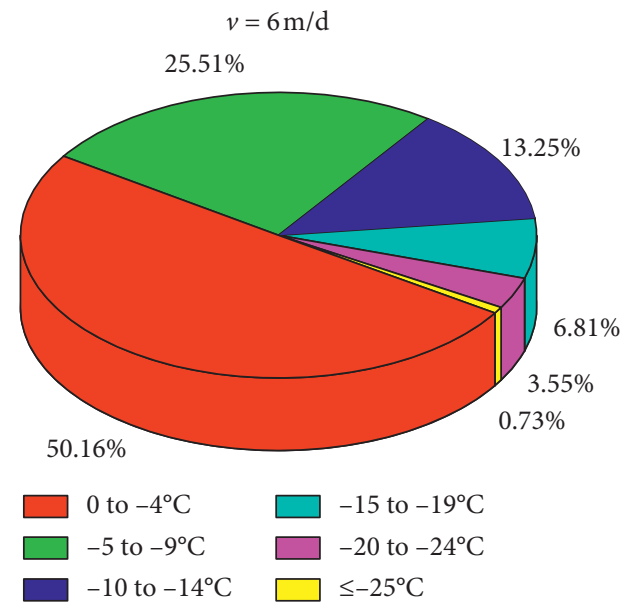

(c)

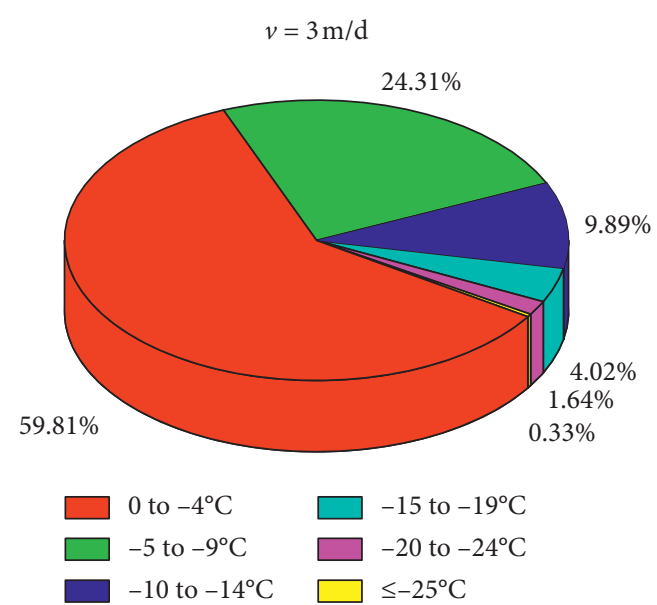

(b)

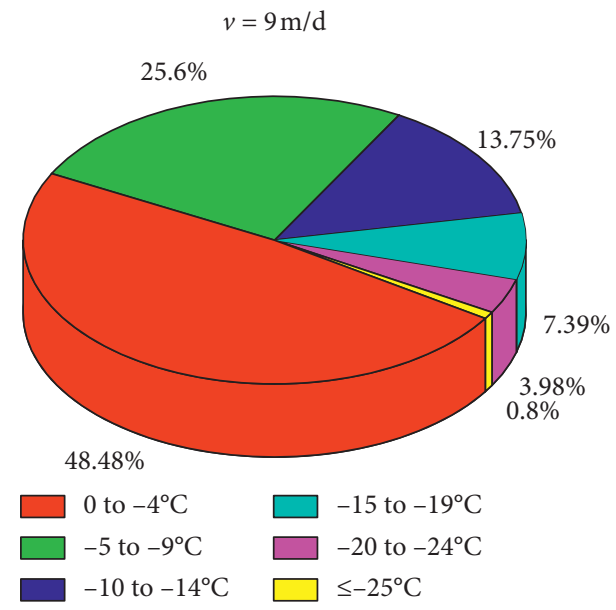

(d)

Figure 9: The proportional relationship between the frozen area $S_{(T, T-\Delta)}$ of the temperature range $(T, T-\Delta)$ and the whole frozen area $S_{T=0}$ under the action of seepage field with a flow rate of (a) 0 , (b) 3 , (c) 6 , and (d) $9 \mathrm{~m} /$ day.

TABLE 3: The average temperature of the temperature field.

\begin{tabular}{lc}
\hline$v$ (m/day) & $\bar{T}\left({ }^{\circ} \mathrm{C}\right)$ \\
\hline 0 & -5.78 \\
3 & -5.86 \\
6 & -7.31 \\
9 & -7.50 \\
\hline
\end{tabular}

range $(T, T-\Delta)$ and the whole frozen area $S_{T=0}$ under different flow rate conditions was calculated, as shown in Figure 9. The average temperature of the entire frozen wall was calculated using the weighted average algorithm as shown in Table 3.

Figure 9 and Table 3 show that compared with the no flow rate, when the seepage velocities were 3,6 , and $9 \mathrm{~m} /$ day, the proportion of frozen zone in the temperature range of 0 to $-4^{\circ} \mathrm{C}$ was reduced from $60.57 \%$ to $59.81 \%, 50.16 \%$, and $48.48 \%$, respectively; the proportion of frozen areas in the temperature range of -5 to $-9,-10$ to $-14,-15$ to -19 , and -20 to $-24^{\circ} \mathrm{C}$ increased from $24.14 \%, 9.62 \%, 3.83 \%$, and $1.53 \%$ to $24.31 \%, 9.89 \%, 4.02 \%$, and $1.64 \% ; 25.51 \%, 13.25 \%$, $6.81 \%$, and $3.55 \%$; and $25.60 \%, 13.75 \%, 7.39 \%$, and $3.98 \%$, respectively. The average temperature of the freezing temperature field was reduced from $-5.78^{\circ} \mathrm{C}$ to $-5.86,-7.31$, and $-7.50^{\circ} \mathrm{C}$, respectively. This showed that as the seepage velocity increased, the frozen area formed by single pipe decreased; the proportion of the low-temperature zone increased; and the average temperature of the temperature field decreased.

\section{Conclusions}

In this paper, the shape of freezing front was simplified using a segmentation-equivalent method. The analytical expression of the steady-state temperature field of single freezing pipe under the action of seepage field was derived, and the accuracy of the analytical solution was verified using a physical model test. The verification results showed that the calculated results of the analytical solution were highly consistent with the experimental results, so the steady-state temperature field under the seepage field could be mathematically described based on the formulas derived in this paper. The results of the model test and calculation can be summarized as follows: 
(1) The model test results showed that when the seepage velocity was $0,3,6$, and $9 \mathrm{~m} /$ day, the time required for the temperature field formed by a single freezing pipe to enter the stable freezing phase was $28,40,24$, and $20 \mathrm{~h}$, respectively, and the frozen area of the steady-state freezing temperature field was $17.97 \times 10^{4}, \quad 15.77 \times 10^{4}, \quad 3.84 \times 10^{4}, \quad$ and $3.05 \times 10^{4} \mathrm{~mm}^{2}$, respectively. This indicated that seepage with a velocity greater than $6 \mathrm{~m} /$ day had a significant effect on the extended range of the steadystate temperature field of a single freezing pipe.

(2) The calculation results of the formulas showed that compared with no flow rate, when the seepage velocity was 3, 6, and $9 \mathrm{~m} /$ day, the proportion of frozen area below $-5^{\circ} \mathrm{C}$ increased from $39.43 \%$ to $40.19 \%$, $49.84 \%$, and $51.52 \%$, respectively, and the average temperature of the freezing temperature field was reduced from -5.78 to $-5.86,-7.31$, and $-7.50^{\circ} \mathrm{C}$, respectively. This showed that as the seepage velocity increased, the area of the single-pipe freezing zone decreased, the proportion of the low-temperature zone increased, and the average temperature of the temperature field decreased.

\section{Data Availability}

The data used to support the findings of this study are available from the corresponding author upon request.

\section{Conflicts of Interest}

The authors declare that they have no conflicts of interest.

\section{Acknowledgments}

This research was funded by the National Natural Science Foundation of China (grant nos. 51878005, 51778004, and 51374010).

\section{References}

[1] H. Cai, Z. Liu, S. Li, and T. Zheng, "Improved analytical prediction of ground frost heave during tunnel construction using artificial ground freezing technique," Tunnelling and Underground Space Technology, vol. 92, Article ID 103050, 2019.

[2] B. Wang, C. X. Rong, H. Cheng, Z. S. Yao, and H. B. Cai, "Research and application of the local differential freezing technology in deep alluvium," Advances in Civil Engineering, vol. 2020, Article ID 9381468, 15 pages, 2020.

[3] B. Wang, C. X. Rong, J. Lin, H. Cheng, and H. B. Cai, "Study on the formation law of the freezing temperature field of freezing shaft sinking under the action of large-flow-rate groundwater," Advances in Materials Science and Engineering, vol. 2019, Article ID 1670820, 20 pages, 2019.

[4] H. Cheng, Freezing Method and Technology of Deep Alluvium, Science and technology of China press, Beijing, China, 2016, in Chinese.

[5] R. A. Sudisman, M. Osada, and T. Yamabe, "Experimental investigation on effects of water flow to freezing sand around vertically buried freezing pipe," Journal of Cold Regions Engineering, vol. 33, no. 3, Article ID 04019004, 2019.

[6] X. M. Zhou, L. F. Su, C. J. He et al., "Horizontal ground freezing method applied to tunneling of Beijing underground railway system," Chinese Journal of Geotechnical Engineering, vol. 21, no. 3, pp. 319-322, 1999, in Chinese.

[7] F. T. Yue, P. Y. Qiu, G. X. Yang, and R. J. Shi, "Design and practice of freezing method applied to connected aisle in tunnel under complex conditions," Chinese Journal of Geotechnical Engineering, vol. 28, no. 5, pp. 660-663, 2006, in Chinese.

[8] D. Y. Li, A. Z. Lv, Q. H. Zhang et al., "Analysis of freezing method for construction of connected aisle in Nanjing metro tunnels," Chinese Journal of Rock Mechanics and Engineering, vol. 23, no. 2, pp. 334-338, 2004.

[9] H. B. Cai, H. Cheng, L. M. Peng et al., "Model test on displacement field of double-route metro constructed with horizontal freezing method," Chinese Journal of Rock Mechanics and Engineering, vol. 28, no. 10, pp. 2088-2095, 2009, in Chinese.

[10] Z. H. Wang, X. R. Zhu, G. X. Zeng et al., "The experimental researches on the ground freezing with liquid nitrogen under water flowing," Journal of Zhejiang University, vol. 32, no. 5, pp. 534-540, 1998.

[11] X. M. Zhou, M. S. Wang, and X. Z. Zhang, "Model test research on the formation of freezing wall in seepage ground," Journal of China Coal Society, vol. 30, no. 2, pp. 196-201, 2005.

[12] E. Pimentel, A. Sres, and G. Anagnostou, "Large-scale laboratory tests on artificial ground freezing under seepage-flow conditions," Géotechnique, vol. 62, no. 3, pp. 227-241, 2012.

[13] R. C. Huang, B. M. Chang, Y. S. Tsaic et al., "Influence of seepage flow on temperature field around an artificial frozen soil through model testing and numerical simulations," in Proceedings of the Southeast Asian Geotechnical Conference, pp. 973-978, Singapore, 2013.

[14] F. Z. Li, H. Ding, and X. Z. Zhang, "Model test research of formation law of double-row-pipe freezing wall in water rich sand layer under seepage," Chinese Journal of Rock Mechanics and Engineering, vol. 38, no. 2, pp. 386-395, 2019.

[15] H. Victor, Die Frostausbreitung Beim Künstlichen Gefrieren von Böden unter dem Einfluss Strömenden Grundwassers, Vol. 42, Institut für Bodenmechanik und Felsmechanik, Karlsruhe, Germany, 1969.

[16] R. L. Harlan, "Analysis of coupled heat-fluid transport in partially frozen soil," Water Resources Research, vol. 9, no. 5, pp. 1314-1323, 1973.

[17] N. G. Trupak, Ground Freezing in Shaft Sinking, Coal Technology Press, Moscow, Russia, in Russian, 1954.

[18] B. V. Bakholdin, Selection of Optimized Mode of Ground Freezing for Construction Purpose, State Construction Press, Moscow, Russia, in Russian, 1963.

[19] F. J. Sanger and F. H. Sayles, "Thermal and rheological computations for artificially frozen ground construction," Engineering Geology, vol. 13, no. 1-4, pp. 311-337, 1979.

[20] N. Tobe and O. Akimoto, "Temperature distribution formula in frozen soil and its application," Refrigeration, vol. 54, no. 622, pp. 665-673, 1979, in Japanese.

[21] Y.-M. Lai, Z. Wu, Y. Zhu, and L. Zhu, "Nonlinear analysis for the coupled problem of temperature and seepage fields in cold regions tunnels," Cold Regions Science and Technology, vol. 29, no. 1, pp. 89-96, 1999.

[22] P. Yang and A. R. Pi, "Study on the effects of large groundwater flow velocity on the formation of frozen wall," 
Chinese Journal of Geotechnical Engineering, vol. 23, no. 2, pp. 167-171, 2001.

[23] G. M. Xu, "Study on mechanical characteristics and multiphysical coupling problems of rock at low temperatures," Chinese Journal of Rock Mechanics and Engineering, vol. 26, no. 5, p. 1078, 2007.

[24] X. D. Hu, W. Guo, and L. Y. Zhang, "Analytical solution of steady state temperature field of a few freezing pipes in infinite region," Journal of China Coal Society, vol. 38, no. 11, pp. 1953-1960, 2013, in Chinese.

[25] X.-d. Hu, W. Guo, L.-y. Zhang, J.-t. Wang, and X. Dong, "Mathematical models of steady-state temperature fields produced by multi-piped freezing," Journal of Zhejiang University-Science A, vol. 17, no. 9, pp. 702-723, 2016.

[26] X.-d. Hu, T. Fang, and L.-y. Zhang, "Analytical solution to temperature distribution in frozen soil wall with wavy boundaries by single-row- and double-row-piped freezing," Cold Regions Science and Technology, vol. 145, pp. 208-228, 2018.

[27] X. D. Hu, F. Zhao, S. Y. She, and C. Shu, "Equivalent parabolic arch method of average temperature calculation for straight double-row-pipe frozen soil wall," Journal of the China Coal Society, vol. 37, no. 1, pp. 28-32, 2012, in Chinese.

[28] X.-d. Hu, L. Han, and Y.-g. Han, "Analytical solution to temperature distribution of frozen soil wall by multi-rowpiped freezing with the boundary separation method," Applied Thermal Engineering, vol. 149, pp. 702-711, 2019.

[29] B. L. Kurylyk, J. M. McKenzie, K. T. B. MacQuarrie, and C. I. Voss, "Analytical solutions for benchmarking cold regions subsurface water flow and energy transport models: one-dimensional soil thaw with conduction and advection," Advances in Water Resources, vol. 70, pp. 172-184, 2014.

[30] M. Vitel, A. Rouabhi, M. Tijani, and F. Guérin, "Modeling heat transfer between a freeze pipe and the surrounding ground during artificial ground freezing activities," Computers and Geotechnics, vol. 63, pp. 99-111, 2015.

[31] M. Vitel, A. Rouabhi, M. Tijani, and F. Guérin, "Modeling heat and mass transfer during ground freezing subjected to high seepage velocities," Computers and Geotechnics, vol. 73, pp. 1-15, 2016.

[32] M. Vitel, A. Rouabhi, M. Tijani, and F. Guérin, "Thermohydraulic modeling of artificial ground freezing: application to an underground mine in fractured sandstone," Computers and Geotechnics, vol. 75, pp. 80-92, 2016.

[33] A. Marwan, M.-M. Zhou, M. Zaki Abdelrehim, and G. Meschke, "Optimization of artificial ground freezing in tunneling in the presence of seepage flow," Computers and Geotechnics, vol. 75, pp. 112-125, 2016.

[34] J. Scheidegger, J. Busby, C. Jackson, F. McEvoy, and R. Shaw, "Coupled modelling of permafrost and groundwater: a case study approach," British Geological Survey Commissioned Report, National Environment Research Council, Swindon, UK, 2017.

[35] R. Hu, Q. Liu, and Y. Xing, "Case study of heat transfer during artificial ground freezing with groundwater flow," Water, vol. 10, no. 10, p. 1322, 2018.

[36] C. Grenier, H. Anbergen, V. Bense et al., "Groundwater flow and heat transport for systems undergoing freeze-thaw: intercomparison of numerical simulators for 2D test cases," Advances in Water Resources, vol. 114, pp. 196-218, 2018.

[37] S. Huang, Y. Guo, Y. Liu, L. Ke, G. Liu, and C. chen, "Study on the influence of water flow on temperature around freeze pipes and its distribution optimization during artificial ground freezing," Applied Thermal Engineering, vol. 135, pp. $435-445,2018$.

[38] S. B. Huang, Q. S. Liu, A. P. Cheng et al., "A coupled hydrothermal model of fractured rock mass under low temperature and its numerical analysis," Rock \& Soil Mechanics, vol. 39, no. 2, pp. 735-744, 2018.

[39] M. A. Alzoubi, A. Nie-Rouquette, and A. P. Sasmito, "Conjugate heat transfer in artificial ground freezing using enthalpy-porosity method: experiments and model validation," International Journal of Heat and Mass Transfer, vol. 126, pp. 740-752, 2018.

[40] M. A. Alzoubi, A. Madiseh, F. P. Hassani, and A. P. Sasmito, "Heat transfer analysis in artificial ground freezing under high seepage: validation and heatlines visualization," International Journal of Thermal Sciences, vol. 139, pp. 232-245, 2019.

[41] A. Bejan, Convection Heat Transfer, John Wiley \& Sons, Hoboken, NJ, USA, 2013. 